\title{
Peronismo e perenidade - A longa trajetória de um movimento em constante mutação
}

Gilberto Maringoni ${ }^{1}$

GRIMSON, Alejandro, ¿Qué es el peronismo? - De Perón a los Kirchner, el movimiento que no deja de conmover la política argentina, Siglo Veintuno Editores, Buenos Aires. 2019.

\section{Resenha recebida em: $30 / 01 / 2020$ \\ Resenha aprovada em: 29/04/2020}

A literatura sobre a vida, o legado e o impulso político gerado por Juán Domingo Perón (18951974) é vasta e variada na Argentina. O ex-coronel do Exército governou o país por dois mandatos, entre 1946-55, e por pouco menos de nove meses, entre 1973-74, sempre eleito de forma consagradora. Sua influência na vida política nacional se consolidou por meio de uma presença marcante e, sobretudo, por uma ausência que contribuiu para a formação de um personagem mítico. Golpeado, alijado do poder e levado a um exílio compulsório de quase duas décadas, Perón deu origem ao movimento que se tornou uma espécie de eixo definidor da vida pública por mais de sete décadas e gerou a esperança da afirmação de um país soberano, que se pautaria pela justiça social e por oportunidades para todos.

O ex-presidente construiu as bases essenciais do Estado argentino, no momento em que a indústria e a classe operária urbana se consolidavam em meio à Guerra Fria. O peronismo é um caso clássico do que se convencionou chamar de populismo latino-americano ${ }^{2}$. Mas sua perenidade e

\footnotetext{
${ }^{1}$ Doutor em História Social pela FFLCH-USP, professor adjunto de Relações Internacionais da Universidade Federal do ABC (UFABC), desenvolve atualmente a pesquisa "Populismo e oportunidade histórica - Conceito impreciso, classificações equivocadas e generalizações duvidosas”. Endereço: Rua Pimenta Bueno, 405 - 03060-000, São Paulo, SP. Email: gilberto.maringoni@ufabc.edu.br.

${ }^{2} \mathrm{O}$ chamado populismo da primeira metade do século XX na América Latina foi expressão própria de sociedades de capitalismo tardio, de industrialização e urbanização aceleradas e de consequentes deslocamentos de grandes contingentes humanos do campo para a cidade. O conceito de populismo é elástico e complexo. Michael L. Conniff, organizador de Populism in Latin America busca compreender os parâmetros do fenômeno: "O mais próximo que conseguimos chegar de uma descrição sintética do populismo latino-americano pode ser expresso desta forma: populistas foram líderes que mantiveram relacionamentos carismáticos com massas de apoiadores e que venceram eleições com regularidade" (CONNIFF, 1999, p. 7). O Dicionário de Política, organizado por Norberto Bobbio, ressalta que: “O populismo não conta
} 
multiplicidade de facetas são de difícil definição e tornam impossível encontrar algo semelhante ao redor do mundo. Há uma constante batalha pelos sentidos do peronismo, que garante sua sobrevivência não como corrente ou sentimento político, mas como espaço público de disputas.

"Sobre o peronismo e sobre seus protagonistas foram escritas bibliotecas inteiras" ${ }^{3}$, constatou Alejandro Horowicz (2016, p. 13), autor de Los cuatro peronismos, lançado originalmente em 1985. Diante desse aluvião de informações e reflexões, o antropólogo argentino Alejandro Grimson decidiu realizar um ensaio panorâmico, buscando na visão de conjunto estabelecer parâmetros e pontos de apoio para responder à pergunta que dá título ao seu livro, ¿Qué es el peronismo?

Evidentemente, a pergunta não tem resposta única. Ao examinar um objeto em permanente mutação, o autor busca "escapar das análises unidimensionais para chegarmos a uma abordagem multidimensional". Em suas palavras, "Não existe o peronismo tal como conhecemos sem o antiperonismo. O peronismo-antiperonismo é uma configuração relacional, um modo de divisão, uma linguagem e uma forma de conflito" (p. 22). O espectro dessa influência é tão amplo, a ponto de confirmar a máxima de que na Argentina todos são peronistas, até a oposição.

Grimson divide seu livro em oito partes, nas quais tenta seguir uma cronologia histórica linear, que vai das origens do movimento, em 1945, até a derrota de Cristina Kirchner para Maurício Macri, nas eleições presidenciais de 2015. O sumário é assim construído:

efetivamente com uma elaboração teórica orgânica e sistemática” (BOBBIO, 2004, p. 980). Margarita López Maya, por sua vez, assinala: "O populismo não é, estritamente falando, um movimento sociopolítico, nem um regime, ou um tipo de organização, mas fundamentalmente um discurso que pode estar presente no interior de organizações, movimentos ou regimes muito diferentes entre si" (LÓPEZ MAYA, 2004, p. 5) . Recentemente, John B. Judis refletiu: "[Uma] importante característica das campanhas e partidos populistas (...) é que eles geralmente funcionam como sinais de alerta de crises políticas. Movimentos populistas americanos emergiram apenas em circunstâncias muito especiais" (JUDIS, 2016, p. 13-16). Entre as "circunstâncias especiais" citadas, podemos arrolar perdas de referências políticas, sociais e de identidade por parte de grandes contingentes populacionais e sua posterior (re) identificação com um líder ou chefe. O estudo pioneiro de referência em nosso país sobre o fenômeno é O populismo na política brasileira, de Francisco Weffort. Para esse autor, "O populismo é fenômeno das regiões atingidas pela intensificação do processo de urbanização" (WEFFORT, 1986, p. 28). Octavio Ianni, em O colapso do populismo no Brasil (1967), constata que: "O populismo sempre foi, malgrado distorções político-ideológicas que lhe são inerentes, um mecanismo de politização das massas" (IANNI, 1975, p. 108). É difícil estabelecer parâmetros canônicos às várias manifestações do populismo no continente. Há, no entanto, um denominador comum: seriam situações em que formas de representação anteriores entram em colapso e novos canais associativos e de representação ainda não estão constituídos. Esse é o traço comum definidor comum em obras de vários autores que buscaram definir o conceito.

${ }^{3}$ Todas as traduções deste artigo são nossas. 
1.O 17 de outubro de 1945 e o surgimento do peronismo. 2. O ano de 1945: as origens do peronismo em uma sociedade racista e de classe. 3. 1956: apogeu e crise dos antiperonismos. 4. Perón e os jovens Montoneros. O choque entre a ala ortodoxa e a ala esquerda do peronismo. 5. Perón, López Rega e o personagem maldito da história peronista. 7. As origens do kirchnerismo. O peronismo e a recuperação da política. 8. O peronismo e o kirchnerismo em seus labirintos. De 54\% até a derrota em 2015 (págs. 5-7).

A opção cronológica se dá pelo que aparenta ser o objetivo central do livro, o de fazer um balanço panorâmico da mais importante vertente política argentina, em um notável esforço agregador e sintético das tensões que marcam uma trajetória histórica - contraditoriamente - não linear. Não é a primeira obra a buscar classificar o peronismo. O já citado Alejandro Horowicz, em 1985, dividiu o fenômeno - como o título de seu livro indica - em quatro fases: a primeira, que cobre o surgimento do peronismo até o golpe de 1955, a segunda, da chamada "Revolução Libertadora" até a volta do líder ao país, em 1973, a terceira, deste ano ao golpe militar de 1976 e a quarta, cobrindo o período da ditadura (HOROWICZ, 2016). São opções metodológicas similares, que permitem visão de conjunto e contextualizada com tensões existentes na arena internacional.

Grimson utiliza em sua investigação extensa bibliografia analítica e histórica argentina e jornais e revistas do país. Aqui reside certo desequilíbrio no uso das fontes. Os periódicos constantes na bibliografia cobrem apenas os anos de 1945-46, o que pode explicar uma análise factual mais cuidadosa sobre os anos inaugurais do peronismo, com detalhes da luta política cotidiana, característica menos observada na análise dos períodos posteriores. Ao mesmo tempo, nos últimos capítulos - que tratam da década menemista (1989-99) e da ascensão de Nestor e Cristina Kirchner - a narrativa se torna mais fluida e há um encadeamento narrativo no qual se percebe a reinvenção do kirchnerismo como movimento que sobrevive não apenas a ditaduras, mas às suas próprias rupturas internas.

Ao longo de três quartos de século - a partir de seu surgimento, em 1945 - o peronismo viveu fases distintas, chegou a se descolar da figura de seu patrono e envolveu setores frontalmente díspares. 
É o caso da Triple A ${ }^{4}$ e dos Montoneros ${ }^{5}$, nos anos 1970. O discurso de unidade nacional do próprio Perón buscava eliminar fronteiras político-ideológicas entre seus apoiadores, que tinham no culto ao líder a marca de coesão mais visível.

Se para seus próprios defensores a classificação do que seria o peronismo se constitui em tarefa difícil, tampouco os opositores logram melhor desempenho nessa tentativa. As oligarquias argentinas jamais tentaram entender o fenômeno como marca política, cultural e identitária de maiorias empobrecidas beneficiadas por direitos sociais concretos. Para o topo da pirâmide social, "A adesão popular ao peronismo só poderia ser explicada pela corrupção ou pela manipulação" e jamais por uma escolha racional, pontua o autor (p. 11). Nesse diapasão, o peronismo expressaria uma espécie de rebaixamento da política e adentraria o terreno da demagogia e da troca de favores fisiológicos.

$\mathrm{O}$ antiperonismo, por mais paradoxal que seja, antecede em muito o surgimento do personagem que lhe dá título. Vale a pena examinarmos um trecho de El siglo de Perón - Ensayo sobre las democracias hegemónicas, de Alain Rouquié, lançado em 2017:

\begin{abstract}
Na segunda metade do século XIX, a República Argentina recorre à imigração europeia para desenvolver seu potencial de riqueza e para integrar-se ao mercado mundial. (...) Povoada pela Europa, olha para o Velho Mundo. (...) Os argentinos, no período mais próspero de sua história, entre 1880 e 1930 não se sentem em absoluto sulamericanos. (...) Em Buenos Aires se chega a afirmar que a Argentina é "o único país branco ao sul do Canadá” (ROUQUIÉ, 2017, p. 26-27).
\end{abstract}

Um componente racista e discriminatório contra índios e negros torna-se elemento constitutivo da sociedade platina. A ideia da eliminação da barbárie emerge como ideia-chave da

\footnotetext{
${ }^{4}$ A Triple A, ou AAA (Aliança Anticomunista Argentina), foi uma organização paramilitar terrorista de extrema-direita, criada nos porões do peronismo. Atuou entre os anos 1973-76 e teve relações estreitas com a CIA, como se revelou em 1981. Seu líder, José López Rega (1916-89), fora secretário particular de Perón durante o exílio na Espanha e tornou-se ministro da Seguridade Social (1973-75) nas gestões do próprio líder e de sua viúva, Isabelita. A organização é acusada de assassinar direta ou indiretamente mais de 1,5 mil lideranças da esquerda peronista, nas disputas internas do movimento. Grimson apresenta duas hipóteses sobre o surgimento da Triple A: 1. A organização teria sido fundada após a morte de Perón, sem que este tivesse interferido no processo e 2. A de que seria um plano do ex-presidente, executado por López Rega. Para as duas hipóteses, o autor apresenta evidências, mas ressalta: "A polêmica colocada nesses termos é estritamente política" (pág. 215).

${ }^{5}$ Os Montoneros se constituíam em um grupo guerrilheiro formado na aba esquerda do peronismo, a partir do final dos anos 1960. Teve influência de setores progressistas da Igreja Católica e da Revolução Cubana. Era formado em grande parte por jovens de classe média que desenvolveram ações armadas até os primeiros anos da ditadura militar (1976-83), quando foi dizimado. A existência de organizações com posições políticas extremas e opostas no interior do peronismo como a Triple A e os Montoneros - mostra a rarefeita definição política e ideológica do movimento.
} 
construção nacional de um país de unificação tardia, o que corresponde à anulação do mestiço e do provinciano. Não à toa, o romance de Domingos F. Sarmiento (1811-1888), Facundo, civilização e barbárie (1845), classifica o caudilho de província como ente quase desumanizado. A acusação de bárbaro perpassa todo aquele visto como entrave à construção nacional, o autocrata local, o "selvagem" do Sul e, a partir da virada do século, o trabalhador indócil.

Assim, a primeira imagem do peronismo a escandalizar as altas classes portenhas, em 17 de outubro de 1945, foi a de trabalhadores se refrescando nos olhos d'água da Praça de Maio, em frente à Casa Rosada. Na capa dos jornais, o título de uma foto clássica era "Com as patas na fonte”. A cena acontecera em meio à concentração de 300 mil pessoas vindas das periferias da capital para ouvir o coronel e ex-Secretário do Trabalho, que acabara de sair da prisão para entrar ruidosamente na cena política. Grimson assinala que:

Essa Nação europeia e branca se concebia e se desenhava sobre o imaginário de uma sociedade homogênea. Portanto, "o outro" dessa civilização - a barbárie, o de baixo, o popular - podia ter diferentes destinos: ser exterminado, ser incorporado através de mecanismos educativos ou, quando ambas alternativas fracassavam, ser excluído”. (p. 109).

A expressão emocional mais forte contra os de baixo passou a ser o ódio de classe. Esse sentimento oligárquico atávico sedimenta o antiperonismo desde então (p. 109).

O peronismo em sua primeira década soube atender parcialmente às demandas da base da sociedade, ao mesmo tempo em que apresentava um caráter e autoritário, sem necessariamente ser ditatorial, assinala Grimson. Foram estabelecidas legislação social para os trabalhadores e educação católica obrigatória nas escolas, acesso cada vez mais amplo à moradia e à vida urbana e restrições às liberdades públicas, entre outras medidas.

Perón queria colocar-se acima dos conflitos de classe e gerar um projeto nacional com amplo consenso ou unanimidade por parte dos setores políticos argentinos. Porém, nada disso aconteceu. As disputas sociais, as demandas operárias e as reações patronais em seu conjunto não permitiram a construção de um acordo de "meio-termo justo". (p. 120).

Por quase dez anos, as classes dominantes suportaram uma ambiguidade que lhes era incômoda. A política argentina incorporou as multidões, cujo controle era realizado com um misto de 
concessões e repressão. O pacto foi brutalmente rompido pela direita no golpe de 1955. O nacionalismo populista tornou-se intolerável tanto interna quanto externamente. Para a Casa Branca, que incentivara as derrubadas de Jacobo Árbenz (Guatemala) e Getúlio Vargas (Brasil) no ano anterior, a situação não admitia negociações. Após o bombardeio da Praça de Maio pela aviação da Marinha, em 16 de junho - com mais de 300 mortes - a ruptura institucional se consuma três meses depois. O exílio de 18 anos na Espanha gerou o Perón mítico.

"Em 1955 se abriu uma etapa do antiperonismo recalcitrante e virulento. Nada mais seria igual na história argentina depois desses acontecimentos", sublinha o autor (p. 122). A violenta Revolução Libertadora se constituiu em feroz ditadura. A partir daí, o antiperonismo ganhou contornos mais nítidos: todas as suas facções revelaram-se conservadoras.

A essa altura, o autor pergunta:

\begin{abstract}
Por que o peronismo persistiu ao longo das décadas? A primeira resposta é porque o “outro" realmente existente ao peronismo foram as ditaduras militares. A segunda é que quando podemos encontrar (...) governos não-peronistas democráticos, os condicionamentos econômicos, militares e o dogmatismo do antiperonismo recalcitrante os tornaram inviáveis. (...). A terceira marca do antiperonismo é a defesa das hierarquias. O quarto rasgo é sua combinação de racionalidade com emocionalidade. E o quinto rasgo é seu binarismo” (p. 132).
\end{abstract}

O que seria “o verdadeiro Perón”? A morte do líder - após sua volta e uma eleição consagradora - em julho de 1974, colocou os vários peronismos diante de um vazio avassalador. Pois se o general marcara a história argentina por seu viés de conciliação de contrários, o mito peronista não se mostrou fruto apenas de sua presença, mas - talvez até mais fortemente - da sua ausência, como já mencionado. Ausente pelo exílio e ausente pela morte, Perón se recoloca por seus continuadores e intérpretes variados.

O peronismo nunca foi fenômeno linear. Mas nada embaralhou tanto sua definição como a gestão de Carlos Menem (1989-1999).

O menemismo ganhou (...) com a promessa de um "salariaço" (em oposição aos habituais "tarifaços"). E de uma "revolução produtiva". Em seus dez anos, Menem privatizou até a empresa petroleira YPF, triplicou o desemprego e aumentou a desigualdade. (p. 224). 
Carlos Menem só pode ser entendido na história do peronismo por ter tomado uma importante medida, em 1991: acabar com uma hiperinflação renitente. O Plano Cavallo e a paridade cambial redundaram em crescimento do PIB nos dois primeiros anos de mandato. Mas todo o seu governo representa a antítese do peronismo, por mais vaga que seja essa concepção. O desemprego, a precarização laboral e, especialmente, seu caráter antinacional e neoliberal geraram uma espécie de “desperonização” da vida política. Os movimentos reivindicatórios surgidos a partir de 1996-97 quando se aprofunda a recessão - não se reivindicavam mais peronistas e os dirigentes sindicais dessa tendência sofreram forte desgaste.

A explosão social que se seguiu à quebra do país entre 1999-2002 não tinha lideranças, programa ou estratégias claras a não ser protestar contra o desastre neoliberal. Não era nitidamente de esquerda ou de direita, antevendo em anos mobilizações como a Primavera Árabe ou as jornadas de junho de 2013, no Brasil. Sua marca principal era "que se vayan todos", ou seja, uma convergência pela negação da política.

De acordo com Grimson, depois de eleito, em 2003, Nestor Kirchner teve de reinventar a relação da população com o Estado, o que, na prática, significou uma reinvenção do peronismo. Sua campanha não teve uma simbologia claramente ligada ao antigo líder. Ações emergenciais em favor do emprego, em uma situação de penúria das contas públicas, e a renegociação forçada dos títulos argentinos consolidaram uma gestão que nascera sob o signo da debilidade e da desconfiança. Para o autor, os Kirchner - Nestor e Cristina - souberam compreender a existência de vários peronismos e incorporá-los à ação do poder público. O movimento social historicamente peronista teve de reciclar suas referências.

Quase ao final do livro, Grimson questiona: “O kirchnerismo é o peronismo do século XXI? Ou é uma corrente do peronismo, entre outras?” (p. 278). A pergunta - como tantas nessa vertente profundamente argentina - não tem respostas claras.

Vale notar que depois do corte menemista, quando o peronismo aparentemente perde grande parte de sua identidade, os laços se recompõem pelo alto, pela ação do Estado.

A grande qualidade do livro está em situar para o leitor não especializado na política argentina uma primeira aproximação no conhecimento do jogo de poder e tensões presentes na segunda 
economia da América do Sul, com uma movimentação de forças absolutamente ímpar na cena mundial.

No entanto, se exibe competência analítica e histórica para interpretar o peronismo como fenômeno político, o livro apresenta fortes lacunas ao minimizar a concretização do peronismo como ação de Estado. Não há uma reflexão consistente e abrangente sobre os três mandatos presidenciais de Perón, com suas políticas públicas nas áreas de economia, educação, trabalho e assistência social, ou de como seus governos buscaram atender a pluralidade de demandas políticas surgidas em cada momento histórico. Falta uma análise do que ocorreu com o peronismo durante a última ditadura militar argentina. Em contraste, as administrações peronistas subsequentes - as de Carlos Menem e Nestor e Cristina Kirchner - são analisadas pelo prisma da ação do Estado. Até porque, repetindo, o ressurgimento a partir de 2003 se dá a partir de cima, por iniciativa do poder público.

Grimson apresenta - e não esconde isso - uma visão favorável ao peronismo histórico. No ano de 2020, o autor tornou-se assessor do presidente Alberto Fernández, eleito no ano anterior pela chapa peronista. Apesar desse fato, o livro não se deixa contaminar por partidismos ou falta de equilíbrio analítico.

O fenômeno peronista segue aberto, incorporando personagens e forças variados e mostrando surpreendente capacidade de se renovar. Nas ruas de Buenos Aires costuma-se dizer que ali está a mais forte concretização do realismo mágico latino-americano.

\section{Referências Bibliográfica}

BOBBIO, N., Matteucci, N. E Pasquino, G., Dicionário de Política, Editora UnB e LGE Editora, Brasília, $3^{\text {a }}$. edição 2004.

CONNIFF, Michael L., Populism in Latin America, The University of Alabama Pres, Tuscaloosa, 1999.

HOROWICZ, Alejandro. Los cuatro peronismos. Buenos Aires: Edhasa, 2016.

IANNI, Octávio, O colapso do populismo no Brasil, Editora Civilização Brasileira, Rio de Janeiro, 1975. 
JUDIS, John B., The Populist Explosion: How the Great Recession Transformed American and European Politics, Columbia Global Report, Nova York, 2016.

LÓPEZ MAYA, Margarita, Populismo e inclusión en el caso del proyecto bolivariano, 2004, inédito.

ROUQUIÉ, Alain. El siglo de Perón - Ensayo sobre las democracias hegemónicas. Buenos Aires: Edhasa, 2017.

SARMIENTO, Domingo Faustino. Facundo: civilização e barbárie. Petrópolis: Vozes, 1997.

WEFFORT, Francisco, O populismo na politica brasileira, Editora Paz e Terra, Rio de Janeiro, 1986. 